\title{
Optical, morphological and photocatalytic properties of biobased tractable films of chitosan/donor-acceptor polymer blends
}

\author{
I. Jessop ${ }^{\mathrm{b}}$, J. Albornoz ${ }^{\mathrm{a}}$, O. Ramírez ${ }^{\mathrm{a}}$, B. Durán ${ }^{\mathrm{c}}$, L. Molero ${ }^{\mathrm{a}}, \mathrm{S}$. Bonardd $^{\mathrm{d}}$, G. Kortaberria ${ }^{\mathrm{e}}$, \\ D. Diaz Diaz ${ }^{\mathrm{f}, \mathrm{g}, \mathrm{h}}$, A. Leiva ${ }^{\mathrm{a}}$, C. Saldías ${ }^{\mathrm{a}, *}$ \\ ${ }^{a}$ Departamento de Química Física, Facultad de Química y de Farmacia, Pontificia Universidad Católica de Chile, Macul, 7820436, Santiago, Chile \\ ${ }^{\mathrm{b}}$ Universidad de Tarapacá, Facualtad de Ciencias, Departamento de Química, Laboratorio de Materiales Orgánicos y Poliméricos, Av. General Velásquez 1775, Arica, Chile \\ ${ }^{\mathrm{c}}$ Centro de Investigación en Nanotecnología y Materiales Avanzados, Pontificia Universidad Católica deChile, 7820436, Macul, Chile \\ ${ }^{\mathrm{d}}$ Centro de Nanotecnología Aplicada, Facultad de Ciencias, Universidad Mayor, 8320000, Santiago, Chile \\ e "Materials + Technologies" Group, Polytechnic School, Dpto. Ingeniería Química y M. Ambiente, Universidad País Vasco/Euskal Herriko Unibertsitatea, Pza. Europa 1, \\ San Sebastian, 20018, Spain \\ ${ }^{\mathrm{f}}$ Departamento de Química Orgánica, Universidad de La Laguna, Avda. Astrofísico Francisco Sánchez S/N, 38206, La Laguna, Tenerife, Spain \\ ${ }^{\mathrm{g}}$ Instituto Universitario de Bio-Orgánica Antonio González, Universidad de La Laguna, Avda. Astrofísico Francisco Sánchez 2, 38206, La Laguna, Tenerife, Spain \\ ${ }^{\mathrm{h}}$ Institut für Organische Chemie, Universität Regensburg, Universitätsstr. 31, 93053, Regensburg, Germany
}

\section{A R T I C L E I N F O}

\section{Keywords:}

Biobased tractable films

Photoactivity

Photodegradation

\begin{abstract}
A B S T R A C T
Biobased tractable films consisting of blends of chitosan (CS) with polymer bearing carbazole derivatives as pendant groups and fluorene-thiophene as donor-acceptor units (referred to as DA) were prepared, and their optical, morphological and photocatalytic properties were studied. DA was dissolved in tetrahydrofuran (THF) and mixed with an acidified aqueous solution containing chitosan to obtain chitosan/DA (CS/DA) films by solution casting. The fabricated biobased films were characterized using spectroscopic techniques (FT-IR and UV-vis), thermogravimetry, mechanical assays, contact angle analysis, and atomic force microscopy (AFM). The effects of varying DA compositions and the results of exposure to visible-light irradiation of the films were also analyzed. The results indicated the existence of interactions between chitosan and DA and a potentially profitable light-driven response of these biobased films. This behavior was reflected in the optical, topographical, and contact angle properties of the films, which exhibited different characteristics before and after visible-light exposure. Finally, the photocatalytic performance of the biobased films was tested via the decomposition of methyl orange (MO), as a reaction model system. Our results revealed a significant photocatalytic activity (according to biobased film composition, approximately $64 \%$ and $87 \%$ of methyl orange were degraded under continuous visible-light irradiation for $120 \mathrm{~min}$ ) of the films which is attributed to the combined presence and synergetic effects of the film-forming ability of chitosan and the photoproperties of DA.
\end{abstract}

\section{Introduction}

Over the last decades, donor and acceptor polymers (D-APs) have been extensively studied due to their wide range of potential applications in organic solar cells (Facchetti, 2013), light emitting diodes (Thompson et al., 2005), sensors (Kochergin et al., 2019), energy conversion (Gao et al., 2016), and storage devices (Guo, Li, Yu, Perepichka, \& Meng, 2017). Thus, many synthetic strategies, mainly based on chemical modification, have been developed with the aim to diversify the properties and to achieve a higher versatility for this type of materials (Davis et al., 2017; Deng \& Doyle, 2016; Wu et al., 2017). Importantly, physicochemical and functional aspects are the differentiating elements that prevail when defining the potential technological applications of D-APs (Wang et al., 2017; Yoshioka, Izumi, Shida, Yamaguchi, \& Kobayashi, 2017). Specifically, D-APs intended for use as photoactive materials for photodegradation of aqueous pollutants should exhibit a relatively low optical bandgap with a broad absorption spectrum to adequately absorb e.g., visible-light irradiation (Nath, Chandra, Pradhan, \& Biradha, 2018; Yang, Duan, \& Ran, 2018). Considering this, one approach to generate combined donor-acceptor materials with a low bandgap is based on the incorporation of alternating electron-donating and electron-accepting moieties in a conjugated polymer backbone (DA), which gives rise to intramolecular charge transfer interactions (Liu et al., 2019; Yang, Zhao et al., 2019).

\footnotetext{
* Corresponding author.

E-mail address: casaldia@uc.cl (C. Saldías).
} 
For example, recently, the synthesis of a series of polymers containing benzazoles as deficient electron moieties has been reported (i.e., could act as moderate electron-accepting units), in order to generate low bandgap polymers (Doyranli \& Koyuncu, 2016; Pati, 2016). This behavior can be ascribed to their heteroaromatic characteristics and the presence of polarizable imine groups $(\mathrm{C}=\mathrm{N})$. Thereby, DA polymers emerge as an attractive type of material due to the availability of viable synthesis routes (e.g., by chemical or electrochemical methods), appropriate environmental stability, good conductivity characteristics and chemical functionality (Ghosh, Das, Kumar, Agrawal, \& Zade, 2017; Li et al., 2017). Interestingly, this type of polymers has been reported as metal-free systems to catalyze light-induced reactions (e.g., hydrogen evolution). Moreover, their high potential as metal-free photocatalytic materials allows the design of easier synthesis routes from inexpensive precursor molecules. This could explain why these materials have been the subject of growing research activity over recent years (Kailasam et al., 2016). In spite of this, the main drawback of DA polymersis that they cannot be easily fabricated in tractable formats, e.g., as thin films with suitable mechanical properties (Kim et al., 2018; Root, Jackson, Savagatrup, Arya, \& Lipomi, 2017). Accordingly, this issue considerably limits the current practical use of this type of materials indiverse technological applications (Choi et al., 2017; Fang et al., 2018). Thereby, the fabrication of DA polymer blends with improved tractable and mechanical properties, while keeping the donor-acceptor properties, is an important topic for further investigation (Benten, Mori, Ohkita, \& Ito, 2016; Benten, Nishida, Mori, Ohkita, \& Ito, 2016; Zhou et al., 2016). Consequently, the development and characterization of various types of DA polymer-biopolymer blends have attracted considerable attention over the last decade (Bharmoria et al., 2018; Mohiuddin, Kumar, \& Haque, 2017; Paiuk et al., 2019). In light of the above mentioned conditions, chitosan, a biopolymer widely used in the preparation of a wide variety of blends and composites, is an outstanding candidate that meets the required attributes (Choi, Nam, \& Nah, 2016; Abdul Khalil et al., 2016; Zhang, Zeng, \& Cheng, 2016). Chitosan is a well-known, biodegradable, biocompatible and nontoxic polymer obtained from the deacetylation of chitin with the ability to form micro- and nanocomposite films with diverse polymer types (Lei et al., 2014; Roy, Kim, Zhai, \& Kim, 2020; Rubentheren et al., 2016). Therefore, the presence of chitosan would eventually allow for the improvement of the physicochemical and mechanical properties, such as stability and flexibility of polymer blends (Bonardd et al., 2019; Chen et al., 2018; Saldías et al., 2018). At a molecular level, the exploitation of molecular interactions with the aim of reducing incompatibility or directly attaining compatibility with other polymers is still a challenging task (Méndez-López et al., 2018; Moreno-Serna, Méndez-López, Vásquez-Espinal, Saldías, \& Leiva, 2020). In this context, it is also highly remarkable that chitosan displays a high functionality and chemical versatility in the formation of profitable e.g., non-covalent interactions with different macromolecules (Alhwaige, Ishida, \& Qutubuddin, 2019; Qiao, Ma, Zhang, \& Yao, 2017). Overall, the use of biopolymers in the preparation and characterization of different types of nanocomposite films is considered to be an innovative strategy for minimizing potentially negative environmental impacts (Roy et al., 2020; Yang, Dahlström, Edlund, Lindman, \& Norgren, 2019). For example, the preparation and characterization of films constituted of chitosan and donor (or acceptor) materials (e.g., graphene, polyelectrolytes) have been reported by other authors for potential technological applications (e.g., gas transport, filtration, anticorrosion, biomedical, fuel cell, solar cells, batteries, sensors and supercapacitors) (Ahmed, Mulla, \& Arfat, 2017; Eren, 2019; Yang, Liu, Kong, Kang, \& Ran, 2019; Yu et al., 2020; Zainudin et al., 2018; Zolfagharian, Kaynak, Khoo, \& Kouzani, 2018). However, due to the different hydrophobic/ hydrophilic characters of a blend`s component materials, immiscibility issues, regardless of the composition and nature of the polymers, can arise (Bonardd et al., 2020; Méndez-López et al., 2018). Therefore, there is a need to gain a deep understanding of the optimal methods and conditions for the appropriate preparation of these types of polymeric blend systems. To the best of our knowledge, the questions surrounding polymer blends composed of chitosan and donor-acceptor polymers in the formation of films (CS/DA polymer blend) have been scarcely addressed as of yet. It is important to note that the issue of miscibility of CS/DA polymer blends is also still a challenging task today. Thus, the addition of low amounts of DA polymers is the recommended approach to study and characterize these kinds of systems. In this work, we focused our attention on the preparation and characterization, as well as the study of the photoresponse attributes and photocatalytic performances of CS/DA polymer blend films. The characterization of the samples was performed using FT-IR spectroscopy, UV-vis spectrophotometry, thermogravimetry (TGA), differential scanning calorimetry (DSC), contact angle analysis and atomic force microscopy (AFM). Thus, this study contributes to the rational design of biobased tractable films with potential light-driven responses from a physicochemical perspective, in order to generate alternative materials for relevant technological applications.

\section{Materials and methods}

\subsection{Materials}

Chitosan (CS) $\left(\bar{M}_{v}=70,000 \mathrm{~g} \mathrm{~mol}^{-1}\right.$, with a degree of deacetylation of approximately $70-80 \%$ ), methyl orange $(95.0 \%)$ and sodium hydroxide were purchased from Sigma-Aldrich (Milwaukee, WI, USA). Donor-acceptor polymer poly[(9,9-dihexyl-9H-fluorene-2,7-diyl)-alt-(9(6-(4,7-bis(thiophen-2-yl)-2H-benzo[d][1,2,3] triazol-2-yl)hexyl)-3,6-di (thiophen-2-yl)-9H-carbazole-5',5"-diyl)] (i.e., DA polymer) with a weight average molecular mass $\left(\bar{M}_{w}\right)$ of $8500 \mathrm{~g} \mathrm{~mol}^{-1}$ and a polydispersity index of 1.37 was kindly provided by Professor Dr. Ignacio Jessop from the Universidad de Tarapacá of Chile. THF and acetic acid solvents were purchased from Merck S.A. The water used in all of the experiments was purified by a Millipore Milli-Q system (resistivity higher than $18.2 \mathrm{M} \Omega \mathrm{cm}$ ).

\subsection{Preparation of CS/ DA polymer blend films}

Polymer blend films were prepared directly from stock solutions of DA polymer and chitosan using a solution-casting method. The concentrations used were $1 \% \mathrm{w} / \mathrm{v}$ in THF and $0.5 \% \mathrm{w} / \mathrm{v}$ in $1 \% \mathrm{v} / \mathrm{v}$ acetic acid aqueous solution for DA polymer and chitosan, respectively. The mixed solutions were adjusted to obtain $0.47 \%$ and $1.21 \% \mathrm{w} / \mathrm{w}$ DA polymer in the films. These mixed solutions were vigorously stirred for $24 \mathrm{~h}$, placed into Petri dishes and further dried under vacuum at $35^{\circ} \mathrm{C}$ for a week. The obtained films were washed with $45 \mathrm{~mL}$ of $1 \times 10^{-2} \mathrm{M} \mathrm{NaOH}$ and then rinsed with abundant Milli-Q water. Finally, the films were dried under vacuum at $30^{\circ} \mathrm{C}$ for $48 \mathrm{~h}$.

\subsection{Characterization techniques}

FT-IR and UV-vis spectra of the polymer films were recorded with Nicolet iS10 and Agilent Cary 60 spectrophotometers, respectively. Thermal degradation of the samples was performed using a TGA/ SDTA851 Mettler-Toledo thermobalance, and the data were processed using the STARe version 8.1 program from Mettler. The thermograms were measured in the range between $25^{\circ} \mathrm{C}$ and $600^{\circ} \mathrm{C}$ with a $20^{\circ} \mathrm{C} \mathrm{min}^{-1}$ heating rate under nitrogen atmosphere. The glass transition temperatures, $\mathrm{T}_{\mathrm{g}}$, of each sample were determined by a Mettler-Toledo DSC 821e. The following five cycles were performed: (i) a first heating from $25 \circ \mathrm{C}$ to $200^{\circ} \mathrm{C}$ with a $20^{\circ} \mathrm{C} \mathrm{min}^{-1}$ rate, (ii) an isotherm for $3 \mathrm{~min}$, (iii) a cooling from $200{ }^{\circ} \mathrm{C}$ to $25^{\circ} \mathrm{C}$ using a $20^{\circ} \mathrm{C} \mathrm{min}^{-1}$ rate, (iv) an isotherm for $3 \mathrm{~min}$, and (v) a second heating from $25^{\circ} \mathrm{C}$ to $200{ }^{\circ} \mathrm{C}$ with a $20^{\circ} \mathrm{C} \mathrm{min}^{-1}$ rate. Atomic force microscopy characterization of the samples was performed in tapping mode with a 3110-Nanoscope IV. Water contact angle measurements were 
performed using an optical contact angle apparatus (Data physics OCA 20 system) equipped with a CCD camera with a high-resolution power. The SCA 20 software (Data Physics Instruments) was used for data acquisition. The water contact angle just after deposition $\left(\theta_{i}\right)$ was measured by placing a droplet of $10.0 \mu \mathrm{L} \pm 0.2 \mu \mathrm{L}$ onto the film sample surface. Both, the support and the injecting syringe were maintained at $25.0^{\circ} \mathrm{C}$. Each simple was analyzed three times, and the average values are reported. Measurements of tensile strengths and elastic moduli of film samples were carried out using Insight 10 (MTS Company, Eden Prairie, Minnesota, USA) equipment, following the ASTM D1708-93 standard, with a rate of deformation of $5 \mathrm{~mm} / \mathrm{min}$. The film thicknesses were determined with a hand-held digimatic micrometer (Mitutoyo Corp., Japan) and the average values obtained from ten random points for each sample are given. Each obtained film was of a thickness of approximately $15 \mu \mathrm{m}$.

\subsection{Irradiation and photocatalysis experiments}

The study of the photoresponse behavior and photocatalytic performance of the as-prepared CS/DA polymer filmswas carried out under visible-light irradiation using a1500 W Xe lamp (Santiago, Chile) with a filter cutting off the UV ( $\lambda \leq 420 \mathrm{~nm})$ and infrared light. Specifically, the evaluation of the photocatalytic activities of the CS/DA A and CS/ DA B films was performed by immersion of the respective samples $(0.75 \mathrm{~cm} \times 0.75 \mathrm{~cm})$ into $2 \mathrm{~mL}$ of a $1.0 \mathrm{mM}$ methyl orange (MO) aqueous solution ( $\mathrm{pH}$ was adjusted to 5.5) contained in a quartz spectrophotometer cell. Then, these samples were kept under a constant air flow rate at room temperature and controlled stirring for the duration of the irradiation period. Changes in the absorbance of the dye were monitored using UV-vis spectroscopy at $465 \mathrm{~nm}$ (the wavelength of the maximum absorption of MO).

\section{Results and discussion}

The details on the experimental route used for the synthesis of the DA polymers can be found elsewhere (Jessop et al., 2016). Conveniently, the chemical structure of DA polymer is shown in Scheme S1 (see Supporting Information). An illustration of the film preparation is depicted in Scheme 1. The resultant samples of CS/DA polymer blend films are referred to as A (for $0.47 \% \mathrm{w} / \mathrm{w}$ DA polymer) and B (for 1.21 $\%$ w/w DA polymer) forthwith. Note that low contents of DA polymers were employed in order to not dramatically affect the thermal, mechanical and/or tractable properties of the formed chitosan films, an effect which currently represents a drawback with these types of

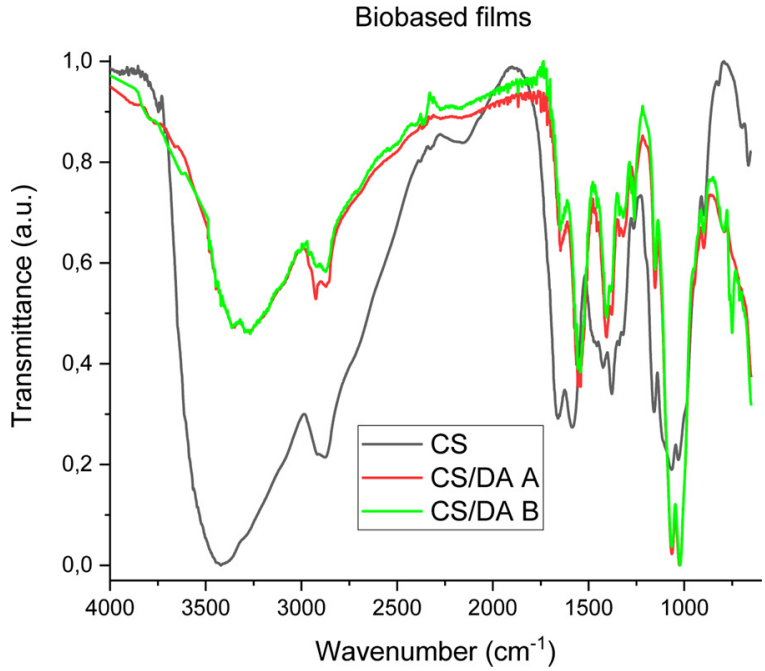

Fig. 1. FT-IR spectra of CS, CS/DA A and CS/DA B films. Comparatively, significant changes in the obtained FT-IR spectra denote the formation of CS/DA polymer films.

polymer blends.

\subsection{FT-IR spectroscopy}

This technique is very useful for the study of possible interactions of the fabricated films on a molecular level. The normalized FT-IR spectra of the prepared samples in the region from 600 to $4000 \mathrm{~cm}^{-1}$ are displayed in Fig. 1. FT-IR spectra of CS/DA A and CS/DA B were recorded to ascertain the eventual compatibility between CS and DA polymers with the aim of forming films. Importantly, the most recognizable signals detected of DA polymer are ranging from approximately $1550-1540 \mathrm{~cm}^{-1}$ and $1065-1020 \mathrm{~cm}^{-1}$, which are ascribed to $\mathrm{C}-\mathrm{C}$ stretch and $\mathrm{C}-\mathrm{H}$ in-plane bending in the aromatic rings, respectively. The spectrum of chitosan shows a broad band at approximately $3400 \mathrm{~cm}^{-1}$, corresponding to $-\mathrm{OH},-\mathrm{NH}_{2}$ and $-\mathrm{NHCO}-\mathrm{CH}_{3}$ vibrations, and a sharper band at $1600 \mathrm{~cm}^{-1}$, which is attributed to the vibration of the $-\mathrm{C}=\mathrm{O}$ originating from amide groups. The band ranging from approximately $1250-1000 \mathrm{~cm}^{-1}$ is attributed to the bending vibrations of the pyranose ring of chitosan. The appearance of intermolecular interactions upon formation of CS/DA films was evidenced by variations in transmittance, sharper signals and significant shifts of
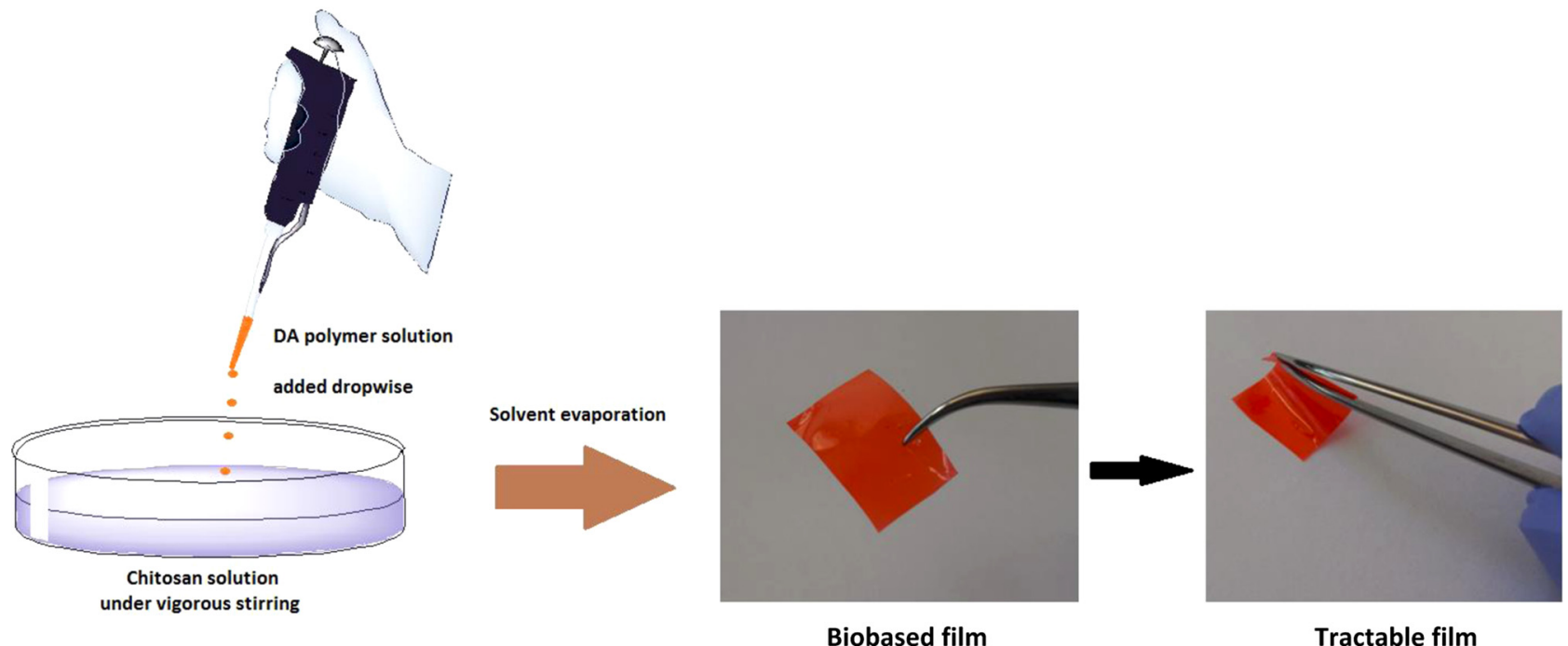

Biobased film

Tractable film

Scheme 1. Representative images of the preparation of biobased tractable films of CS/DA. 

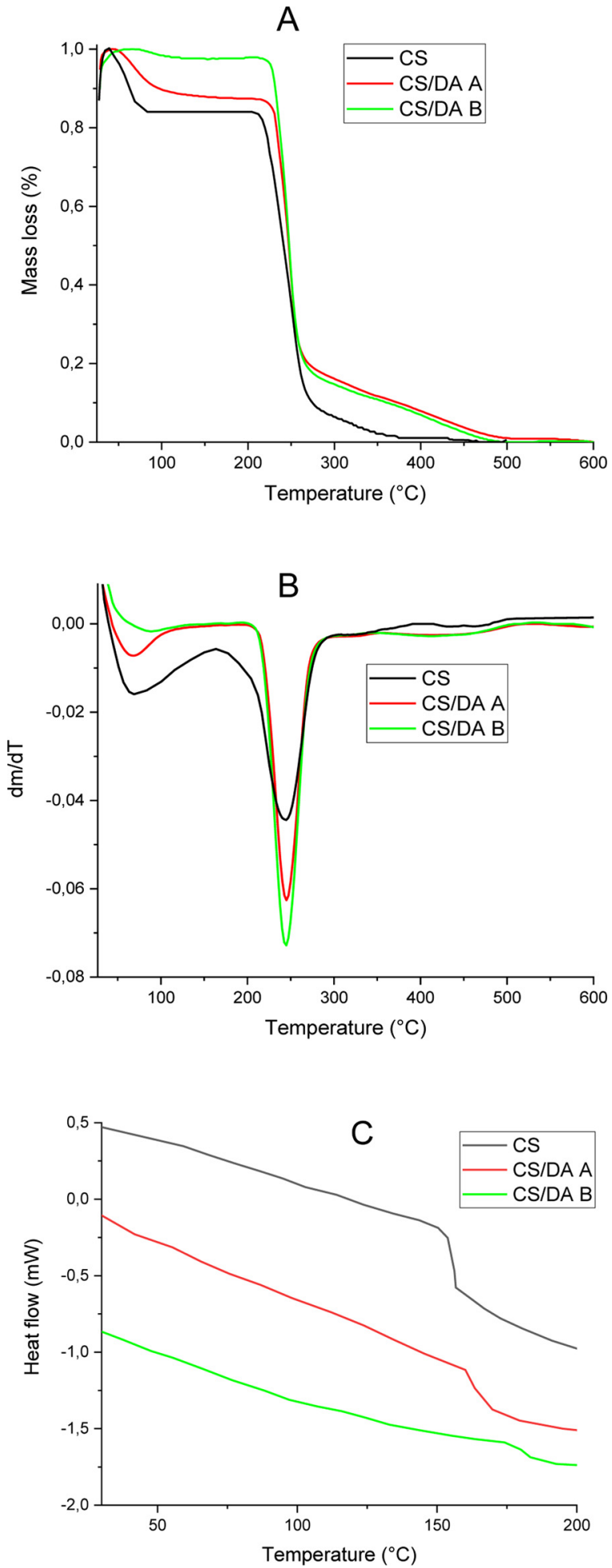

Fig. 2. a) Degradation (TGA), b) differential thermogravimetric analysis (DTGA) curves and c) DSC thermograms for CS, CS/DA A and CS/DA B biobasedfilms. The thermal behavior of the films depends on the incorporated amount of DA polymers.

the bands described above. Importantly, these results could also account for changes in the viscosity of the chemical microenvironment of chitosan due to an incorporation of aromatic rings originating from the DA polymers. In this sense, a rigorous scrutiny of the FT-IR spectra reveals considerable shifts in the $-\mathrm{OH},-\mathrm{NH}_{2}$ and $\mathrm{C}=\mathrm{O}$ bands of chitosan. It is well documented that the formation of polymer films is favored by the existence of hydrogen bonds and long-range molecular interactions (e.g., van der Waals attractive forces). Additionally, moderate shifts observed for carbonyl and pyranose ring functional groups were also induced by intermolecular interactions. It is likely that these functional groups contribute to a lesser extent to the resultant macroand microstructures of the polymer films. The values of the band shifts of the polymer films are summarized in Table S1 (see Supporting information).

\subsection{Thermal measurements}

TGA and DSC analyses were used to assess the thermal behavior of the CS/DA polymer blend films. Degradation (TGA) and differential thermogravimetric analysis (DTGA) curves are shown in Fig. 2a and b. The thermal degradation onset $\left(\mathrm{T}_{\text {onset }}\right)$ and maximum weight loss rate $\left(\mathrm{T}_{\mathrm{md}}\right)$ temperatures of the films are listed in TableS2 as well. The most important weight loss for chitosan occurred between $209^{\circ} \mathrm{C}$ and $266^{\circ} \mathrm{C}$. Using the DTGA curves, $\mathrm{T}_{\mathrm{md}}$ was determined to be approximately $290^{\circ} \mathrm{C}$ for chitosan. Some shifts were observed in the $\mathrm{T}_{\mathrm{md}}$ analysis of the biobased film samples. In general, the temperature values reflect that with increasing DA polymer content in the films, the thermal stability of chitosan is slightly increased. This effect was attributed mainly to changes in the intermolecular interactions and the chemical microenvironment of the chitosan chains, which caused an increase in their thermal stability. Therefore, it can be inferred that the chemical structure of DA chains i.e., condensed aromatic rings, endows the polymer blend with a higher thermal resistance. Interestingly, the initial water content of the chitosan film (ascribed to a temperature range of $45^{\circ} \mathrm{C}-165^{\circ} \mathrm{C}$ ) is clearly diminished upon DA polymer incorporation. Therefore, the hydrophilic character of the chitosan film is also modified when polymer blends are formed. Moreover, in the temperature range of $255^{\circ} \mathrm{C}-500^{\circ} \mathrm{C}, \mathrm{CS} / \mathrm{DA}$ films displayed a higher residue amount compared to bare chitosan films. It is likely that this temperature zone partially corresponds to the region of thermal degradation of condensed aromatic rings.

According to the DSC measurements, $\mathrm{T}_{\mathrm{g}}$ was detected at approximately $155^{\circ} \mathrm{C}$ for bare chitosan (Fig. 2c). Note that various reports in the literature suggest that the value of the glass transition temperature of chitosan depend on diverse parameters, such as humidity content, polydispersity, acetylation degree and presentation format (e.g., film, powder). In our case, the $\mathrm{T}_{\mathrm{g}}$ value reported herein is in good agreement with earlier reports (Bonardd et al., 2019). This aspect is very relevant, because below this temperature a higher rigidity of the chitosan chains is expected. The $T_{g}$ values obtained for all films are listed in Table S2. Considering these temperatures, the incorporation of DA in the polymer films gives rise to an increase in the $\mathrm{T}_{\mathrm{g}}$ temperature of CS. This behavior confirms that the presence of condensed aromatic rings induces a decrease in the mobility of the chitosan chains. Therefore, the presence of DA significantly affects the viscosity of the microenvironment and the cooperative motions of CS chains.

\subsection{UV-vis characterization}

UV-vis spectroscopy is a very useful tool for gaining a better understanding of the electronic, optical and absorption properties of CS/ DA films. The UV-vis spectra of biobased films are shown in Fig. 3. The absorption spectra of CS/DA A and B films presented absorbance peaks at approximately $488 \mathrm{~nm}$ and $482 \mathrm{~nm}$, respectively. As expected, for higher DA amounts, the absorbance of the peak increased (i.e., hyperchromic effect) (El-Sonbati, Diab, \& Serag, 2019). This suggests that an increase in absorbance can be ascribed to the incorporation of DA in the polymer blend films. Overall, the absorption peaks suffered a slight red shift with an increase in the amount of DA, which can be interpreted as a possible variation in the dielectric properties of the chemical environment (Jung et al., 2018). Thus, the polarizability and polarity properties could be affected by charge transfer phenomena due to the 


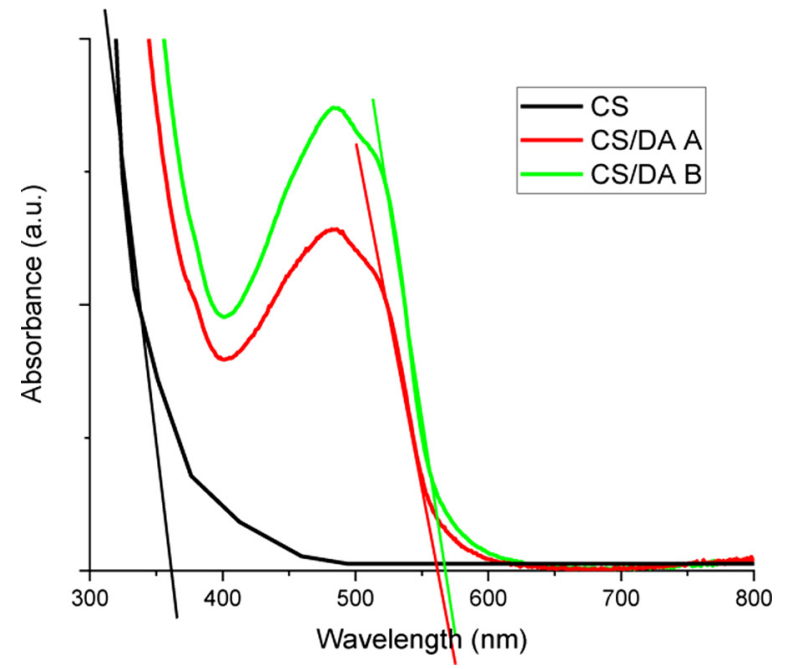

Fig. 3. (a) UV-vis spectra of CS, CS/DA A and CS/DA B films. The straight lines indicate the extrapolated wavelengths for the estimation of the optical band gap.

increase in $\pi$-conjugated aromatic content in the films. Interestingly, the incorporation of low amounts of DA polymer in the biobased films resulted in appreciable changes in the absorption behavior. Thus, the UV-vis spectra confirm notable interactions between CS and DA polymer chains. Considering these results, the optical band gap $\left(E_{g}\right)$ of CS/DA films was estimated using the following equation (Martínez et al., 2019):

$E_{g}=\frac{1242}{\lambda_{t h}}$

where $E g$ represents the optical energy band gap (in eV) and $\lambda_{\text {th }}$ represents the threshold wavelength (in nm) obtained from the onset of the absorption spectrum. The above mathematical expression is usually valid for organic $\pi$-conjugated systems, i.e., DA polymers. The values of $E_{g}$ for CS, CS/DA A and CS/DA B films were $3.5 \mathrm{eV}, 2.1 \mathrm{eV}$ and $2.2 \mathrm{eV}$, respectively. As observed from the $E_{g}$ values, the incorporation of DA decreases the optical band gap compared with bare chitosan film. This behavior can be attributed to the appearance of potential interactions between $\mathrm{R}-\mathrm{X}-\mathrm{R}$ (where $\mathrm{X}=\mathrm{S}$ and $\mathrm{N}$ ) and hydroxyl/amine/carbonyl functional groups of the DA and chitosan polymers, respectively. Both, the increase in concentration and the presence of the chemical structure of highly aromatic donor-acceptor polymers contribute to the charge mobility and electronic transfer processes, which lead to a decrease in the optical band gap values.

\subsection{Mechanical analysis}

Mechanical properties of the biobased tractable films were also studied. For this, a basic mechanical characterization was performed using tensile tests for bare chitosan, CS/DA A and CS/DA B biobased films. Fig. S1 shows the tensile strengths and elastic moduli of each sample. As can be seen from the results, all film samples showed significant values for the measured parameters. The tensile strengths were 12.9 MPa, 35.8 MPa and 47.1 MPa for bare chitosan, CS/DA A and CS/ DA B, respectively. Additionally, the elastic moduli were estimated to be 11.7 MPa, 14.3 MPa and 16.1 MPa, respectively (ordered in the same way). Comparatively, the mechanical performances of chitosan and CS/ DA films, i.e., tensile strengths and elastic moduli,were found to be in the same order of magnitude. Apparently, the elastic modulus tends to slightly increase with increasing amount of DA. In the case of tensile strength values, a considerable increase for CS/DA films compared with bare chitosan film has to be clearly noted. Therefore, the DA polymer acts as a good component in the polymer blend from the perspective of

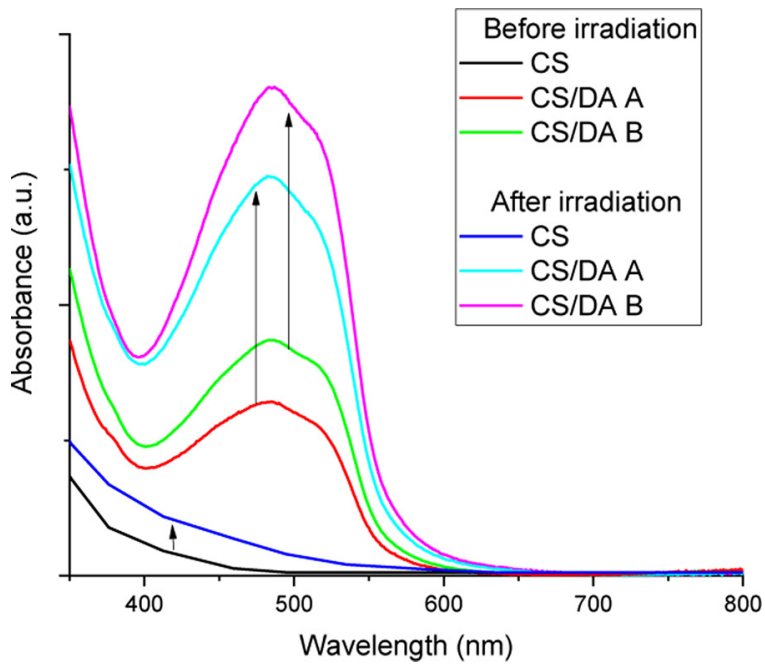

Fig. 4. Comparative UV spectra of irradiated and non-irradiated film samples. The arrows mark the respective changes in the absorbance before and after light exposure.

generating tractable materials. Interestingly, these results allow for the support of the fact that a use of low concentrations of DA diminishes the possibility of obtaining e.g., brittle films. Thereby, the chemical properties of DA polymers contribute to the enhancement of intermolecular forces and film-forming abilities of chitosan, providing higher flexibility (i.e., a higher degree of freedom for the polymer chains) compared with CS/DA film samples.

\subsection{Photoresponse behavior}

To investigate the eventual photo-induced behavior of film samples pertinent experiments using visible light irradiation were conducted. Specifically, a comparative study of different properties before and after $20 \mathrm{~min}$ of exposure to light was carried out. Thereby, optical, topographical and wettability properties were analyzed with the aim of gaining insights into the photoresponse behavior of tractable biobased films. Firstly, the optical behavior revealed notable increases in the respective values of absorbance for irradiated samples compared with non-irradiated ones (Fig. 4). For the chitosan film, a slight change in the absorbance after irradiation was noted. Essentially, chitosan's functional groups do not strongly absorb in the visible region, which helps confirm that the presence of DA polymers is the determinant for the optical behavior of the films. In contrast, the $E_{g}$ values (CS/DA A $2.0 \mathrm{eV}$ and CS/DA B $2.1 \mathrm{eV}$ ) corresponding to light-exposed biobased films remain almost unaltered with respect to the values before exposure. Additionally, it can be noted that the absorbance of the film samples exposed to light increased considerably. This suggests that the probability of electronic transitions is incremented for irradiated films, i.e., interband transitions are more favorable (Li, Li, \& Chen, 2020; Li, Ge, Han, \& Shi, 2019). It is important to mention that no color change was detected in the film samples after 20 min of irradiation.

Atomic force microscopy images of the studied films before and after irradiation are shown in Fig. 5. Before exposure to light, a relatively smooth and homogenous surface was observed. Note that the surface morphology shows a gradual change with increasing amount of $\mathrm{DA}$ in the film. These variations are reflected in the values of the average maximum height (AMH) and root mean square roughness (RMS) of each sample (TableS3). Interestingly, after irradiation, a separation of phases can be observed. This can be ascribed to the appearance of microdomains or aggregates of DA polymers on the matrix surface of chitosan films. These observations are consistent with the different values of the AMH and RMS profiles obtained for the irradiated films with respect to non-irradiated ones. Unlike chitosan 


\section{Beforeirradiation}

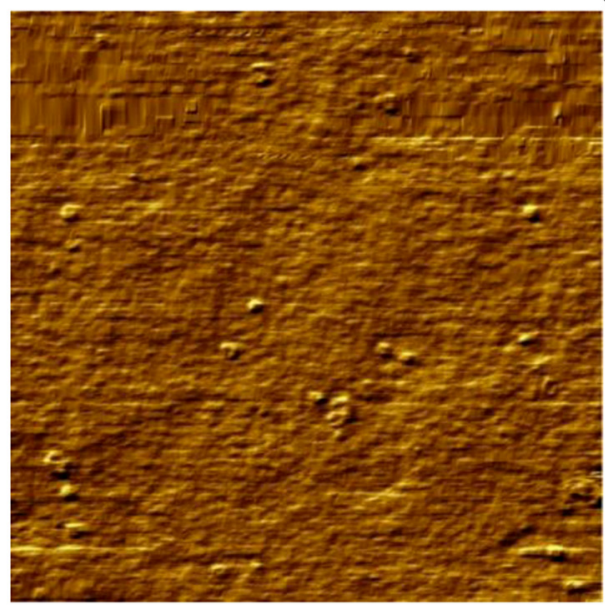

After irradiation

\section{CS}

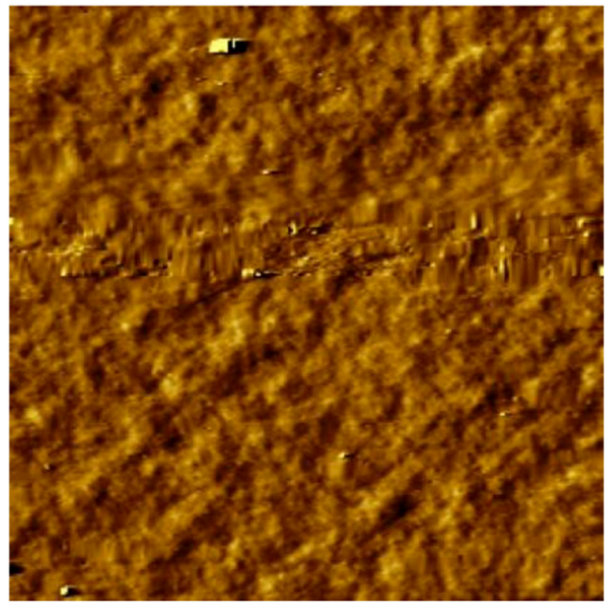

\section{CS/DA A}
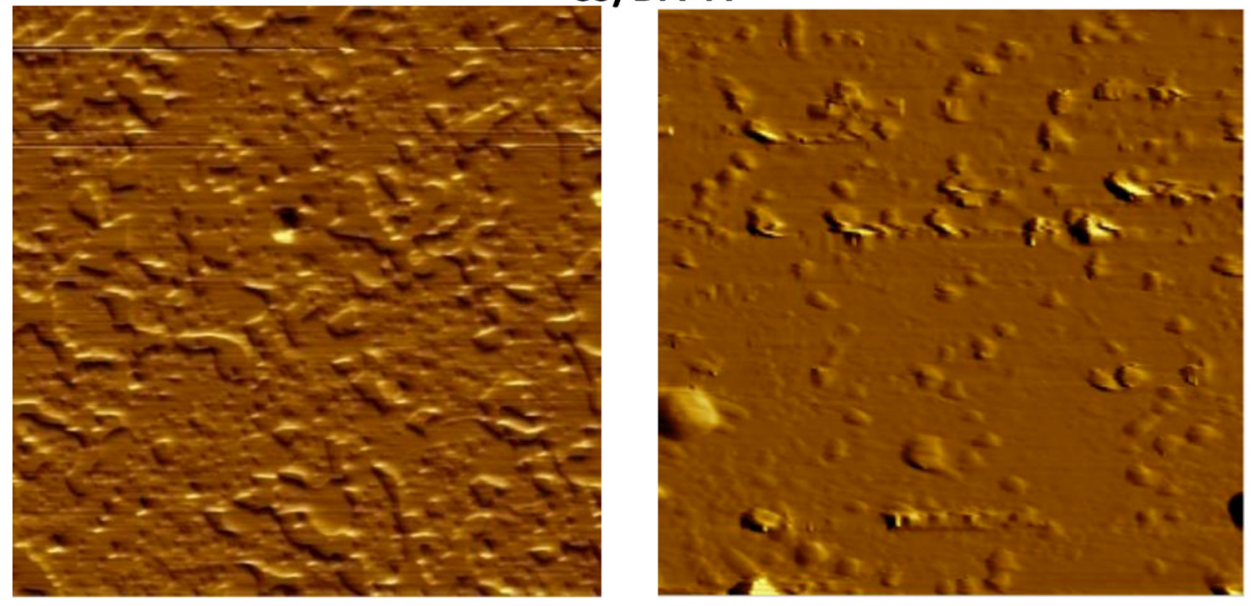

\section{CS/DA B}
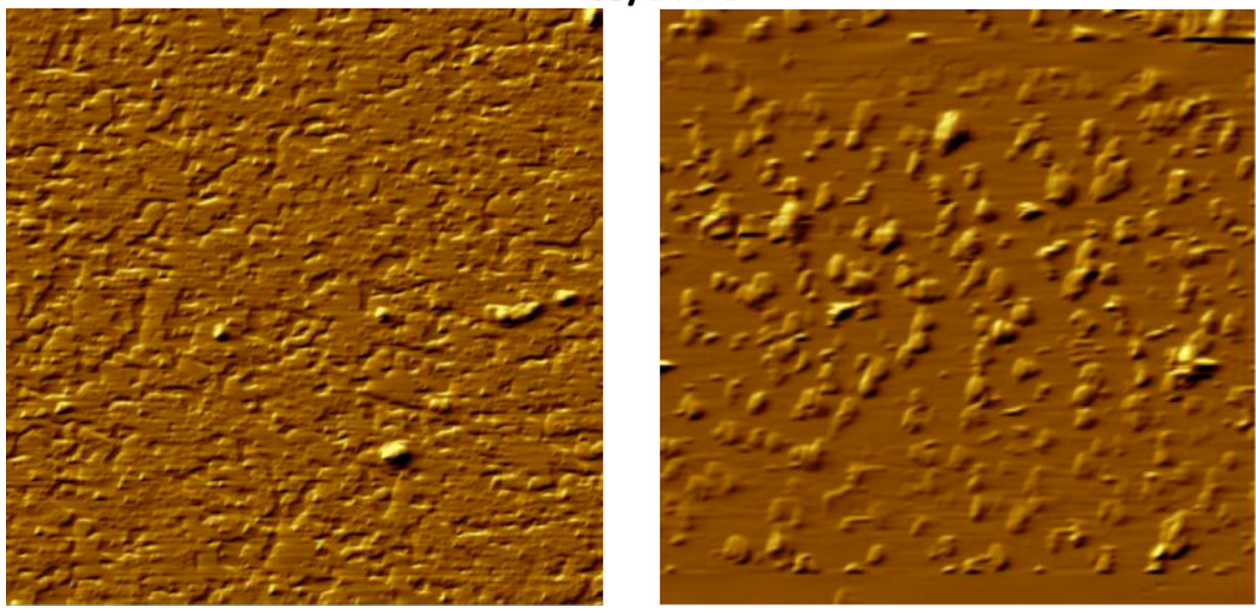

Fig. 5. $\left(3 \times 3 \mu \mathrm{m}^{2}\right)$ AFM images of CS, CS/DA A and CS/DA B film samples. The variations in topography of the samples are attributed to the amount of DA polymers present and the light exposure of the films.

samples, the after light exposure, films displayed lower RMS values than non-irradiated ones, which is a consequence of the comparatively smoother surface initially displayed. Alternatively, the values of AMH were determined to be higher for the irradiated samples, likely due to the contribution of the formed aggregates on the film surface. Therefore, evidence suggests that light-induced processes give raise to significant variations in film surface morphology. This can be attributed to surface nanoscale reorientation or rearrangements of determined regions of polymer chains in CS/DA films.

The variations in the hydrophilic/hydrophobic balance for non-irradiated and irradiated films were studied using contact angle measurements. This way, light-induced changes of the wettability 

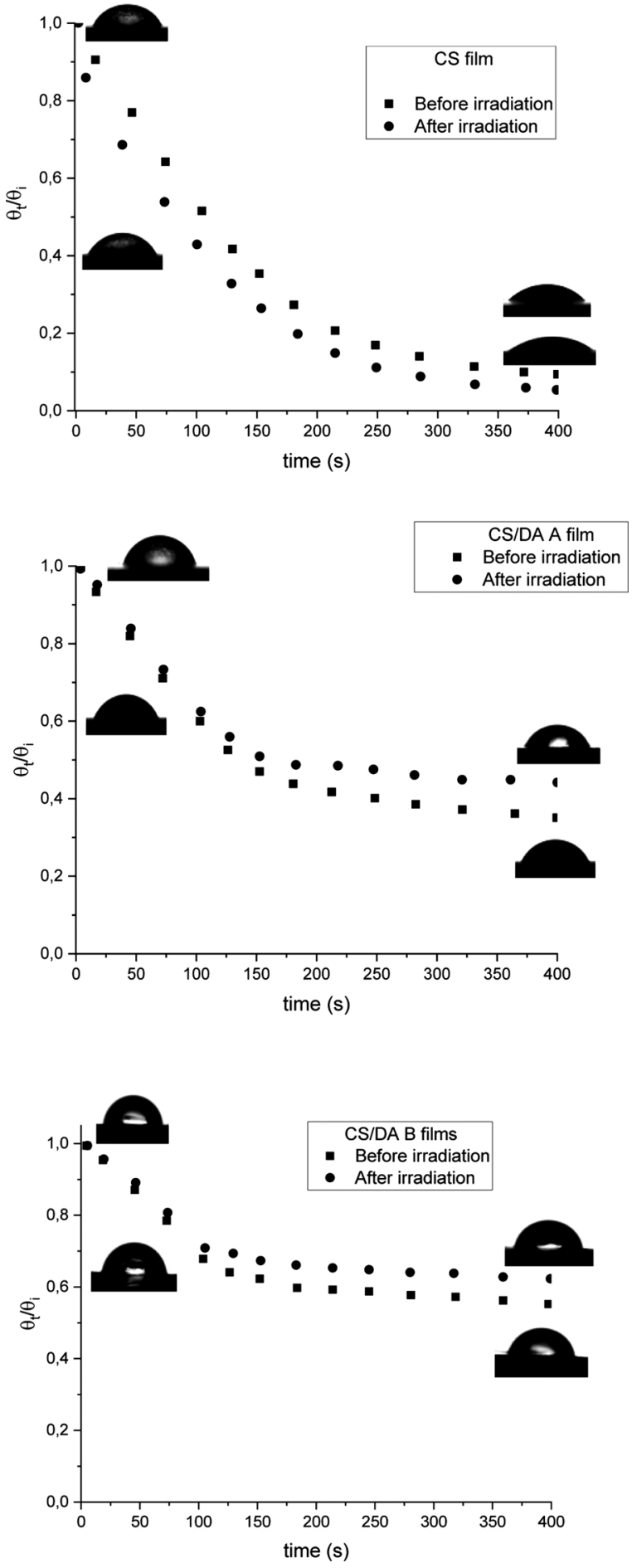

Fig. 6. Mean observed water contact angle evolution over approximately $7 \mathrm{~min}$ of monitoring of the CS/DA films before and after irradiation.

properties of biobased films could be determined. Fig. 6 shows the contact angles (CA) of the deposited water droplets on the films, measured over time $(t)$. Globally, the behavior of non-irradiated and irradiated samples shows a CA decrease over time, as adsorption/spreading mechanisms take place. The CA vs $t$ curves were fitted using the following mathematical expression (Bertolino, Cavallaro, Lazzara, Milioto, \& Parisi, 2018):

$\frac{\theta_{t}}{\theta_{i}}=e^{-k t^{n}}$ where $\frac{\theta_{t}}{\theta_{i}}$ is the ratio between the water CA values at time $t$ and just after the deposition of the drop on the film surface, $t$ is the measurement time of the CA; $k$ is a kinetic constant that mainly depends on the chemical structure and functionality of the surface film; and $n$ is an exponent related to the mechanism involved. Note that $n$ can be in the range between 0 and 1 for pure adsorption and pure spreading phenomena, respectively (Farris et al., 2011). The fitting parameters are listed in Table S4. In our case, the $\mathrm{R}^{2}$ values indicate that the data fit relatively well to Eq. (2). $n$ values in the range from $0.53(0.57)$ to $0.73(0.79)$ were calculated before (after) irradiation for all film samples. These intermediate values of $n$ can be understood by considering that the CA decreasing processes are controlled by a combination of both, the adsorption, and the spreading mechanism. However, based on the obtained values it can be noted that the spreading mechanism is predominant for CS/DA films. This is consistent with the hydrophobic nature of CS/DA films. Additionally, the $k$ values are evidence that the exposure of light also affects the kinetics of the adsorption/spreading processes. The presence of DA polymers (for both non-irradiated and irradiated samples) resulted in an increase in $\theta_{i}$ values, indicating that a change in the hydrophobic/hydrophilic balance of the film surfaces occurred. This finding agrees with the appearance of microdomains on the surface of the irradiated CS/DA films evidenced by the AFM images (Fig. 5). This result indicates that high mobility regions (e.g., $\pi$-conjugated moiety bonded to alkyl chain) of DA polymers undergo lightinduced rearrangement processes that give rise to a preferential orientation towards the surface of the films (i.e., more hydrophobic environment) (Scheme 2).

\subsection{Photocatalytic properties}

In order to confirm the photocatalytic properties of CS/DA biobased films, degradation of methyl orange was performed as a model reaction. In the presence of biobased films, the aqueous medium, and after $2 \mathrm{~h}$ of reaction time (Fig. 7), approximately $64 \%$ (using CS/DA A film) and 87 $\%$ (using CS/DA B film) of MO under visible light irradiation was removed. This reflects the predominant effect of light irradiation on the process of degradation of MO organic molecules mediated by photoactive biobased films. The disappearance of the $465 \mathrm{~nm}$ absorption peak and the shift of the $275 \mathrm{~nm}$ absorption peak to $250 \mathrm{~nm}$ indicates that the $-\mathrm{N}=\mathrm{N}-$ bond was broken. Note also that the latter signals show a relative diminishing of the absorbances. This behavior results in a corresponding gradual fading of the orange color of the solution. Several authors have reported lower molecular weight species are formed as reaction products (e.g., new benzene rings containing amine groups) after the light-induced degradation reaction of MO. The above also comprises the light-induced formation of reactive species, such as peroxide (e.g., $\mathrm{H}_{2} \mathrm{O}_{2}$ ) and radical (e.g., ${ }^{\circ} \mathrm{OH}, \mathrm{O}_{2}$ ) molecules, which promote MO photodegradation (Scheme 3). Similarly, the same reaction was tested in dark conditions, no reaction was observed, as no significant change at $465 \mathrm{~nm}$ was detected for MO in the UV-vis absorption spectrum. Importantly, to examine whether the bare chitosan film affects the reduction rate or not, the same experiment was performed and no reaction could be observed. Therefore, the presence of photoactive DA polymers in CS/DA films plays a key role in the catalytic process of MO photodegradation.

Additionally, kinetic studies were performed based on the obtained data, which were processed considering a pseudo-first order mechanism with respect to MO. According to this, Eq. (3) was employed as follows (Saldías et al., 2018):

$\operatorname{Ln}[M O]_{t}=\operatorname{Ln}[M O]_{0}-k^{\prime} t$

where $k^{\prime}$ is the apparent rate constant, $[\mathrm{MO}]_{\mathrm{t}}$ and $[\mathrm{MO}]_{0}$ are the concentrations of MO at time $t$ and the initial time, respectively. As the absorbance of MO is proportional to the concentration of MO in the reaction medium, it is possible to replace the concentration terms by 


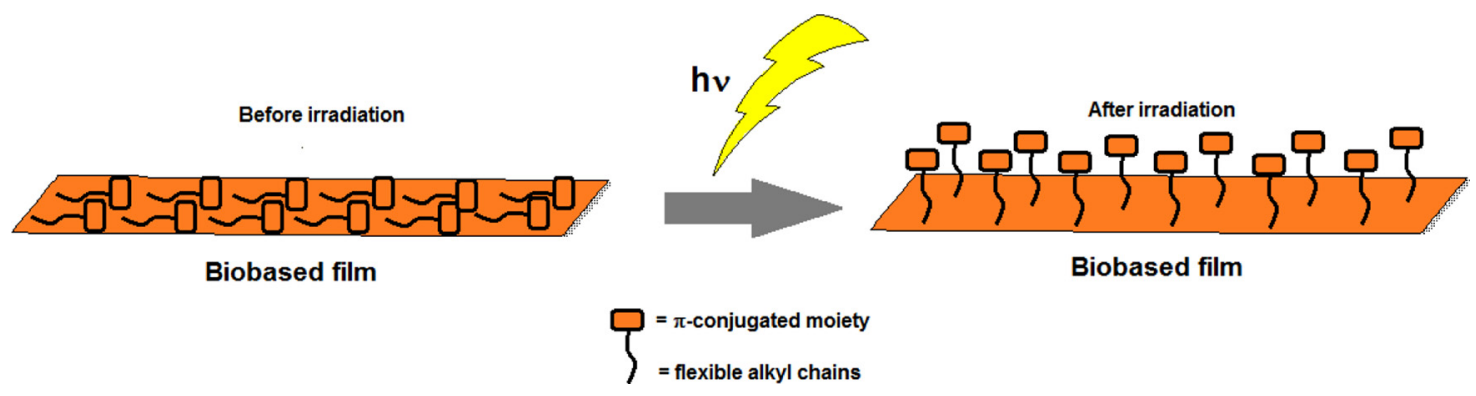

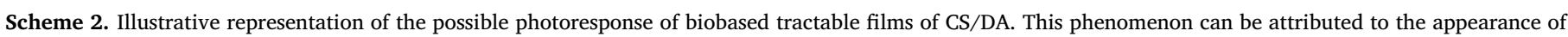
aggregates on the film surface.

the absorbance values (A), as shown in Eq. (4):

$\operatorname{Ln} A_{t}=\operatorname{Ln} A_{0}-k^{\prime} t$

where $A_{t}$ and $A_{O}$ are the absorbance values at time $t$ and the initial time, respectively. Thus, a plot of $L n A_{t}$ vs $t$ yields slope $k$ '. The kinetic data obtained for CS/DA films as catalysts are shown to be in agreement with other results e.g., results of metal-based catalysts reported recently in the literature (Drašinac, Erjavec, Dražić, \& Pintar, 2017; Dziike, Franklyn, Durbach, Maubane, \& Hlekelele, 2018; Pirsaheb et al., 2020; Rahmani, Rahmani, \& Zonouzi, 2018; Savastenko, Brüser, \& Maskevich,
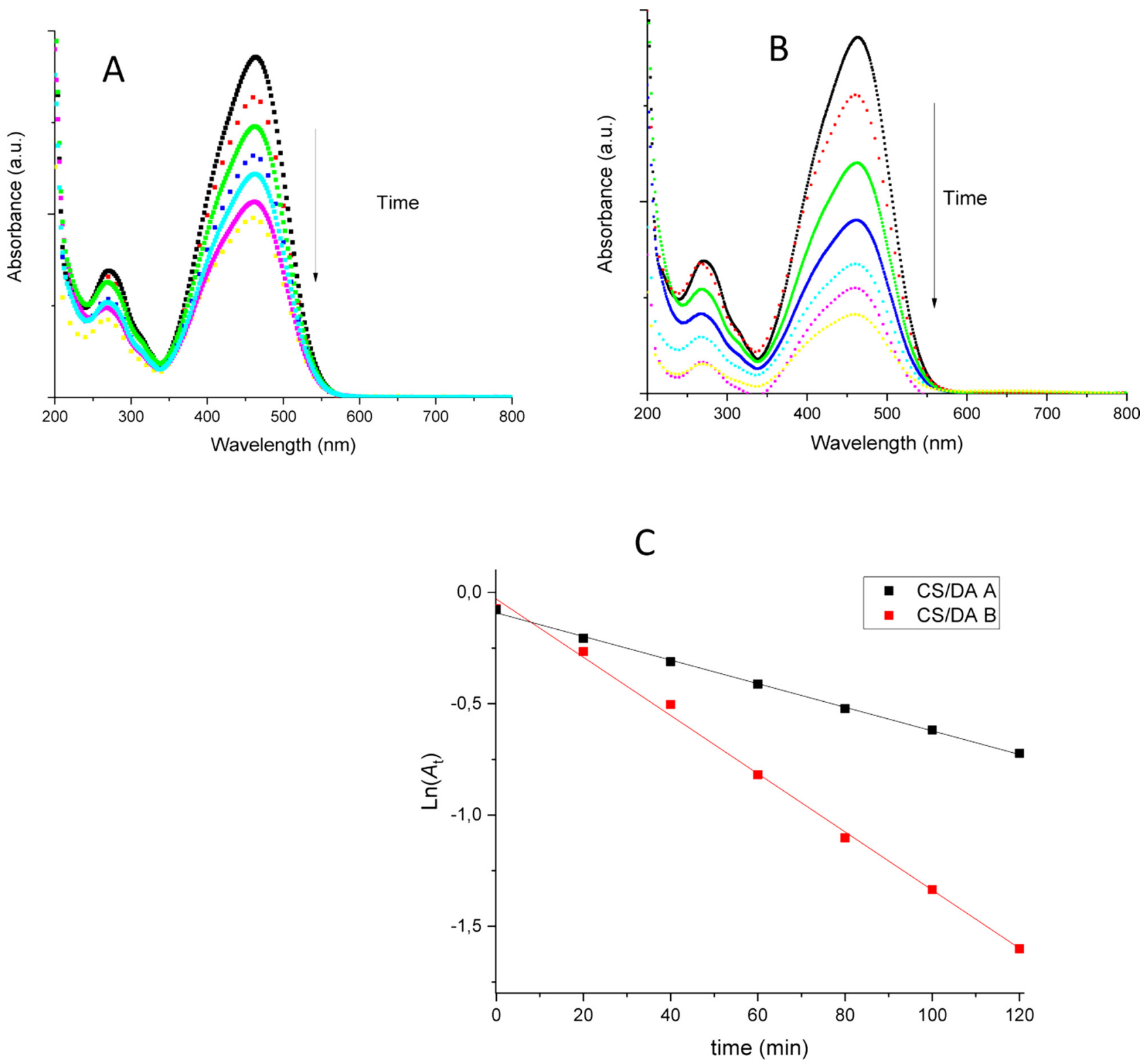

Fig. 7. UV-vis spectra of the photodegradation of MO by the a) CS/DA A and b) CS/DA B film samples, as well as(c) the reduction rates of CS/DA film catalysts. Note that, after film addition a gradual decrease in the absorption band at $465 \mathrm{~nm}$ was registered. The films showed better fittings with reactions of pseudo-first order. 


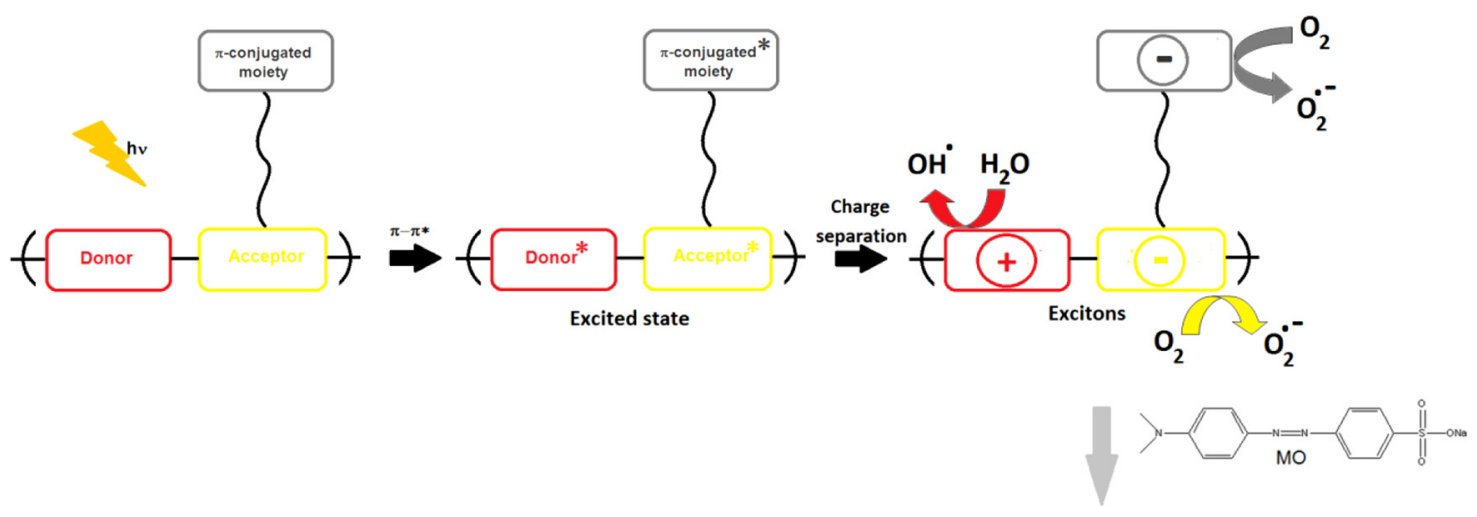

Degradation products

Scheme 3. Proposed mechanism for the photodegradation of methyl orange in the presence of CS/DA films. In this case, the role played by DA polymers is depicted in more detail.

2018). Importantly, these biobased films can offer a high stability and versatility, diversity of presentation formats (e.g., film, fibers), potentially low toxicity in living organisms, low-cost fabrication, high availability of the components, easy processability, among others.

In this context, to assess the recyclability of biobased films, these systems were used four times consecutively, upon washing and rinsing with Milli-Q water after each use. The values of the pseudo rate constant for the 1st, 2nd, 3rd, and 4th cycles obtained from the MO photodegradation reaction are summarized in Table S5. The activities (S) of both films were calculated using the following equation (Sahiner, Butun, Ozay, \& Dibek, 2012):

$S \%=\frac{k_{x}}{k_{1}} ; x=1,2,3$ and 4

where $k_{x}$ is the reduction rate of each of the cycles after use and $k_{1}$ is the reduction rate of the 1st cycle. As observed in Fig. S2, the activities and photodegradation efficiency of MO were systematically diminished after each cycle for both CS/DA films. In spite of this, interesting advantages can be envisioned for these biobased films e.g., this type of catalyst is entirely constituted of compounds of an organic nature; hence, they can be considered to be "all-polymer" catalysts. Additionally, biobased films acting as catalysts would help replace the use of inorganic, expensive and potentially toxic catalysts based on $\mathrm{Rh}, \mathrm{Au}$, $\mathrm{Pt}$, Ir and Ru that commonly display similar or even lower reduction rates after a few cycles of use (Aghakhaninejad, Rahimi, \& Zargari, 2018; Chaker, Chérif-Aouali, Khaoulani, Bengueddach, \& Fourmentin, 2016; Dhanalakshmi, Saravanakumar, Prabavathi, \& Muthuraj, 2020; Masoud, Nourbakhsh, \& Hassanzadeh-Tabrizi, 2017; Vaiano \& Iervolino, 2019; Zhang et al., 2019). It is well-known that the duration, versatility, and performance of a catalyst are crucial aspects, especially for light-driven chemical reactions of technological importance. Thereby, the presented biobased films prepared from renewable sources at relatively low costs have an interesting advantage in technological applications for sequential and long-term uses by providing adequate photocatalytic activity for a wide diversity of potential organic pollutants.

\section{Conclusions}

The present work evidenced that photoactive biobased films can act as adequate and comparatively recyclable materials for light-induced MO degradation. The chitosan/donor-acceptor polymer blend films were prepared using a solution casting method. The route presented is a remarkable method because the presence of low amounts of photoactive (i.e., donor-acceptor) polymers results in light-induced changes in the optical, topographical and wettability properties. These "all- polymer" films can be used as potential photocatalytic materials for the light-driven degradation of toxic and/or industrially relevant organic pollutants. Importantly, these photoactive films result in tractable materials, which is an attribute highly relevant for their potential incorporation in diverse types of smart integrated devices. Consequently, the results of this study offer an enabled organic material for an eventually wide range of photodegradation reactions. Finally, the design and fabrication of these photoactive films with tractable attributes represent an attractive and comparative economically (e.g., use of raw materials, such as chitosan) viable strategy for advanced applications of technological or industrial interest.

\section{CRediT authorship contribution statement}

I. Jessop: Conceptualization, Formal analysis. J. Albornoz: Data curation, Investigation. O. Ramírez: Data curation, Investigation. B. Durán: Supervision, Validation, Visualization, Writing - original draft, Funding acquisition. L. Molero: . S. Bonardd: . G. Kortaberria: . D. Diaz Diaz: . A. Leiva: . C. Saldías: Writing - original draft, Writing review \& editing.

\section{Acknowledgments}

The authors would like to thank Proyecto Inserción Académica (VRA UC, C.S.), FONDECYT11180088 (I.J.) and Distinguished Researcher; BEAGAL18/00166 (D.D.D.). The FONDAP project 15110019 is also acknowledged (A.L.).

\section{Appendix A. Supplementary data}

Supplementary material related to this article can be found, in the online version, at doi:https://doi.org/10.1016/j.carbpol.2020.116822.

\section{References}

Abdul Khalil, H. P. S., Saurabh, C. K., Adnan, A., Fazita, M. N., Syakir, M., Davoudpour, Y., \& Dungani, R. (2016). A review on chitosan-cellulose blends and nanocellulose reinforced chitosan biocomposites: Properties and their applications. Carbohydrate Polymers, 150, 216-226.

Aghakhaninejad, S., Rahimi, R., \& Zargari, S. (2018). Application of BiVO4 nanocomposite for photodegradation of methyl orange. Multidisciplinary Digital Publishing Institute Proceedings, 9, 52.

Ahmed, J., Mulla, M., \& Arfat, Y. A. (2017). Mechanical, thermal, structural and barrier properties of crab shell chitosan/graphene oxide composite films. Food Hydrocolloids, $71,141-148$.

Alhwaige, A. A., Ishida, H., \& Qutubuddin, S. (2019). Poly (benzoxazine-f-chitosan) films: The role of aldehyde neighboring groups on chemical interaction of benzoxazine precursors with chitosan. Carbohydrate Polymers, 209, 122-129.

Benten, H., Mori, D., Ohkita, H., \& Ito, S. (2016). Recent research progress of polymer donor/polymer acceptor blend solar cells. Journal of Materials Chemistry A, 4(15), 
5340-5365.

Benten, H., Nishida, T., Mori, D., Ohkita, H., \& Ito, S. (2016). Ternary blend of conjugated polymers for broadening the absorption bandwidth of polymer solar cells. Journal of Photopolymer Science and Technology, 29(4), 537-540.

Bertolino, V., Cavallaro, G., Lazzara, G., Milioto, S., \& Parisi, F. (2018). Halloysite nanotubes sandwiched between chitosan layers: Novel bionanocomposites with multilayer structures. New Journal of Chemistry, 42(11), 8384-8390.

Bharmoria, P., Hisamitsu, S., Nagatomi, H., Ogawa, T., Morikawa, M.-a., Yanai, N., ... Kimizuka, N. (2018). Simple and versatile platform for air-tolerant photon upconverting hydrogels by biopolymer-surfactant-chromophore Co-assembly. Journal of the American Chemical Society, 140(34), 10848-10855.

Bonardd, S., Morales, N., Gence, L., Saldías, C., Angel, F. A., Kortaberria, G., ... Leiva, A. (2020). Doped poly (3-hexylthiophene) coatings onto chitosan: A novel approach for developing a bio-based flexible electronic. ACS Applied Materials \& Interfaces, 12(11), 13275-13286.

Bonardd, S., Saldías, C., Ramírez, O., Radić, D., Recio, F. J., Urzúa, M., ... Leiva, A. (2019). A novel environmentally friendly method in solid phase for in situ synthesis of chitosan-gold bionanocomposites with catalytic applications. Carbohydrate Polymers, 207, 533-541.

Chaker, H., Chérif-Aouali, L., Khaoulani, S., Bengueddach, A., \& Fourmentin, S. (2016). Photocatalytic degradation of methyl orange and real wastewater by silver doped mesoporous TiO2 catalysts. Journal of Photochemistry and Photobiology A: Chemistry, $318,142-149$.

Chen, J., Cheng, G., Liu, R., Zheng, Y., Huang, M., Yi, Y., \& Deng, H. (2018). Enhanced physical and biological properties of silk fibroin nanofibers by layer-by-layer deposition of chitosan and rectorite. Journal of Colloid and Interface Science, 523, 208-216.

Choi, C., Nam, J.-P., \& Nah, J.-W. (2016). Application of chitosan and chitosan derivatives as biomaterials. Journal of Industrial and Engineering Chemistry, 33, 1-10.

Choi, E. Y., Eom, S. H., Song, C. E., Nam, S. Y., Lee, J., Woo, H. Y., \& Lee, C. (2017). Synthesis and characterization of a wide bandgap polymer based on a weak donorweak acceptor structure for dual applications in organic solar cells and organic photodetectors. Organic Electronics, 46, 173-182.

Davis, N. J., MacQueen, R. W., Jones, S. T., Orofino-Pena, C., Cortizo-Lacalle, D., Taylor, R. G., \& Greenham, N. C. (2017). Star-shaped fluorene-BODIPY oligomers: versatile donor-acceptor systems for luminescent solar concentrators. Journal of Materials Chemistry C, 5(8), 1952-1962.

Deng, Y., \& Doyle, M. P. (2016). Versatile donor-acceptor cyclopropenes in metal carbene transformations. Israel Journal of Chemistry, 56(6-7), 399-408.

Dhanalakshmi, M., Saravanakumar, K., Prabavathi, S. L., \& Muthuraj, V. (2020). Iridium doped $\mathrm{ZnO}$ nanocomposites: Synergistic effect induced photocatalytic degradation of methylene blue and crystal violet. Inorganic Chemistry Communications, 111, Article 107601.

Doyranli, C., \& Koyuncu, F. B. (2016). Carbazole based electrochromic polymers with benzoazole units: Effect of heteroatom variation on electrochromic performance. Express Polymer Letters, 10(9), 762.

Drašinac, N., Erjavec, B., Dražić, G., \& Pintar, A. (2017). Peroxo and gold modified titanium nanotubes for effective removal of methyl orange with CWPO under ambient conditions. Catalysis Today, 280, 155-164.

Dziike, F., Franklyn, P. J., Durbach, S. H., Maubane, M., \& Hlekelele, L. (2018). Synthesis of radially aligned nano-rutile modified with $\mathrm{Au}$ and $\mathrm{Ni}$ for the photodegradation of methyl orange. Materials Research Bulletin, 104, 220-226.

El-Sonbati, A., Diab, M., \& Serag, L. (2019). Polymer complexes. LXXII. Spectroscopic studies, thermodynamics, DNA binding and biological activity of polymer complexes. Applied Organometallic Chemistry, 33(3), e4670.

Eren, E. (2019). Li + doped chitosan-based solid polymer electrolyte incorporated with PEDOT: PSS for electrochromic device. Journal of the Turkish Chemical Society Section A Chemistry, 5(3), 1413-1422.

Facchetti, A. (2013). Polymer donor-polymer acceptor (all-polymer) solar cells. Materials Today, 16(4), 123-132.

Fang, Y., Jin, H., Raynor, A., Wang, X., Shaw, P. E., Kopidakis, N., \& Burn, P. L. (2018). Application of an $\mathrm{A}-\mathrm{A}^{\prime}-\mathrm{A}$-containing acceptor polymer in sequentially deposited allpolymer solar cells. ACS Applied Materials \& Interfaces, 10(28), 24046-24054.

Farris, S., Introzzi, L., Biagioni, P., Holz, T., Schiraldi, A., \& Piergiovanni, L. (2011) Wetting of biopolymer coatings: Contact angle kinetics and image analysis investigation. Langmuir, 27(12), 7563-7574.

Gao, L., Zhang, Z. G., Xue, L., Min, J., Zhang, J., Wei, Z., ... Li, Y. (2016). All-polymer solar cells based on absorption-complementary polymer donor and acceptor with high power conversion efficiency of 8.27\%. Advanced Materials, 28(9), 1884-1890.

Ghosh, S., Das, S., Kumar, N. R., Agrawal, A. R., \& Zade, S. S. (2017). Effect of heteroatom (S/Se) juggling in donor-acceptor-donor (D-A-D) fused systems: Synthesis and electrochemical polymerization. New Journal of Chemistry, 41(20), 11568-11575.

Guo, Y., Li, W., Yu, H., Perepichka, D. F., \& Meng, H. (2017). Flexible asymmetric supercapacitors via spray coating of a new electrochromic donor-acceptor polymer. Advanced Energy Materials, 7(2), Article 1601623.

Jessop, I., Bustos, M., Hidalgo, D., Terraza, C., Tundidor-Camba, A., Pardo, M., Bernede, J. (2016). Synthesis of $2 \mathrm{H}$-benzotriazole based donor-acceptor polymers bearing carbazole derivative as pendant groups: Optical, electronical and photovoltaic properties. International Journal of Electrochemical Science, 11, 9822-9838.

Jung, I., Kim, M., Kwak, M., Kim, G., Jang, M., Kim, S. M., \& Park, S. (2018). Surface plasmon resonance extension through two-block metal-conducting polymer nanorods. Nature Communications, 9(1), 1-9.

Kailasam, K., Mesch, M., B, Möhlmann, L., Baar, M., Blechert, S., ... Thomas, A. (2016). Donor-acceptor-type heptazine-based polymer networks for photocatalytic hydrogen evolution. Energy Technology, 4(6), 744-750.

Kim, W., Choi, J., Kim, J.-H., Kim, T., Lee, C., Lee, S., Kim, T., \& S (2018). Comparative study of the mechanical properties of all-polymer and fullerene-polymer solar cells: The Importance of polymer acceptors for high fracture resistance. Chemistry of Materials, 30(6), 2102-2111.

Kochergin, Y. S., Noda, Y., Kulkarni, R., Škodáková, K., Tarábek, J., Schmidt, J., ... Bojdys, M. J. (2019). Sulfur-and nitrogen-containing porous donor-acceptor polymers as real-time optical and chemical sensors. Macromolecules, 52(20), 7696-7703.

Lei, J., Yang, L., Zhan, Y., Wang, Y., Ye, T., Li, Y., ... Li, B. (2014). Plasma treated polyethylene terephthalate/polypropylene films assembled with chitosan and various preservatives for antimicrobial food packaging. Colloids and Surfaces B, Biointerfaces, $114,60-66$.

Li, J., Li, Z., \& Chen, X. (2020). Thermal detection based on an all polymer device. Sensors and Actuators A: PhysicalArticle 112021.

Li, L., Ge, B., Han, B., \& Shi, W. (2019). Donor-acceptor sequence engineering in $\pi$ conjugated polymers for enhanced hole transport and photocurrent. The Journal of Physical Chemistry C, 123(23), 14253-14260.

Li, Z., Zhang, W., Xu, X., Genene, Z., Di Carlo Rasi, D., Mammo, W., ... Wang, E. (2017) High-performance and stable All-polymer solar cells using donor and acceptor polymers with complementary absorption. Advanced Energy Materials, 7(14), Article 1602722.

Liu, X., Deng, W., Wang, J., Zhang, R., Zhang, S., Galuska, L., \& Ma, D. (2019). Energy level modulation of donor-acceptor alternating random conjugated copolymers for achieving high-performance polymer solar cells. Journal of Materials Chemistry C, 7(48), 15335-15343.

Martínez, N. P., Inostroza-Rivera, R., Durán, B., Molero, L., Bonardd, S., Ramírez, O., \& Saldías, C. (2019). Exploring the effect of the irradiation time on photosensitized dendrimer-based nanoaggregates for potential applications in light-driven water photoreduction. Nanomaterials, 9(9), 1316.

Masoud, M., Nourbakhsh, A., \& Hassanzadeh-Tabrizi, S. A. (2017). Influence of modified CNT-Ag nanocomposite addition on photocatalytic degradation of methyl orange by mesoporous TiO2. Inorganic and Nano-Metal Chemistry, 47(8), 1168-1174.

Méndez-López, M., Moreno-Serna, V., Inostroza-Rivera, R., Ramos, A., Molero, L., Bonardd, S., \& Saldías, C. (2018). Optical and electronic activities of biobased films of chitosan/POTE containing gold nanoparticles: Experimental and theoretical analyses. European Polymer Journal, 108, 235-249.

Mohiuddin, M., Kumar, B., \& Haque, S. (2017). Biopolymer composites in photovoltaics and photodetectors. Biopolymer composites in electronics. Elsevier459-486.

Moreno-Serna, V., Méndez-López, M., Vásquez-Espinal, A., Saldías, C., \& Leiva, Á. (2020). Chitosan/P3HT biohybrid films as polymer matrices for the in-situ synthesis of CdSe quantum dots. Experimental and theoretical studies. Journal of Applied Polymer Science, 137(36), 49075-49090.

Nath, K., Chandra, M., Pradhan, D., \& Biradha, K. (2018). Supramolecular organic photocatalyst containing a cubanelike water cluster and donor-acceptor stacks: Hydrogen evolution and dye degradation under visible light. ACS Applied Materials \& Interfaces, 10(35), 29417-29424.

Paiuk, O., Mitina, N., Slouf, M., Pavlova, E., Finiuk, N., Kinash, N., \& Hevus, O. (2019). Fluorine-containing block/branched polyamphiphiles forming bioinspired complexes with biopolymers. Colloids and Surfaces B, Biointerfaces, 174, 393-400.

Pati, P. B. (2016). Benzazole (B, N, O, S, Se and Te) based DAD type oligomers: Switch from electropolymerization to structural aspect. Organic Electronics, 38, 97-106.

Pirsaheb, M., Hossaini, H., Nasseri, S., Azizi, N., Shahmoradi, B., \& Khosravi, T. (2020) Optimization of photocatalytic degradation of methyl orange using immobilized scoria-Ni/TiO 2 nanoparticles. Journal of Nanostructure in Chemistry, 1-17.

Qiao, C., Ma, X., Zhang, J., \& Yao, J. (2017). Molecular interactions in gelatin/chitosan composite films. Food Chemistry, 235, 45-50.

Rahmani, A., Rahmani, H., \& Zonouzi, A. (2018). Cu (BDC) as a catalyst for rapid reduction of methyl orange: Room temperature synthesis using recycled terephthalic acid. Chemical Papers, 72(2), 449-455.

Root, S. E., Jackson, N. E., Savagatrup, S., Arya, G., \& Lipomi, D. J. (2017). Modelling the morphology and thermomechanical behaviour of low-bandgap conjugated polymers and bulk heterojunction films. Energy \& Environmental Science, 10(2), 558-569.

Roy, S., Kim, H. C., Zhai, L., \& Kim, J. (2020). Preparation and characterization of synthetic melanin-like nanoparticles reinforced chitosan nanocomposite films. Carbohydrate Polymers, 231, Article 115729.

Rubentheren, V., Ward, T. A., Chee, C. Y., Nair, P., Salami, E., \& Fearday, C. (2016). Effects of heat treatment on chitosan nanocomposite film reinforced with nanocrystalline cellulose and tannic acid. Carbohydrate Polymers, 140, 202-208.

Sahiner, N., Butun, S., Ozay, O., \& Dibek, B. (2012). Utilization of smart hydrogel-metal composites as catalysis media. Journal of Colloid and Interface Science, 373(1), $122-128$.

Saldías, C., Díaz, D. D., Bonardd, S., Soto-Marfull, C., Cordoba, A., Saldías, S., ... Leiva, Á (2018). In situ preparation of film and hydrogel bio-nanocomposites of chitosan/ fluorescein-copper with catalytic activity. Carbohydrate Polymers, 180, 200-208.

Savastenko, N., Brüser, V., \& Maskevich, S. (2018). Plasma-assisted synthesis of polymercapped dye-sensitised TiO2-based photocatalysts for methyl orange photodecomposition. SPECTRAL INSTRUMENTS 433.

Thompson, B. C., Madrigal, L. G., Pinto, M. R., Kang, T. S., Schanze, K. S., \& Reynolds, J. R. (2005). Donor-acceptor copolymers for red-and near-infrared-emitting polymer light-emitting diodes. Journal of Polymer Science Part A: Polymer Chemistry, 43(7), $1417-1431$.

Vaiano, V., \& Iervolino, G. (2019). Photocatalytic removal of methyl orange azo dye with simultaneous hydrogen production using Ru-modified Zno photocatalyst. Catalysts, 9(11), 964.

Wang, W., Wang, G., Yang, J., Zhang, J., Chen, L., Weng, C., \& Shen, P. (2017). Effects of alkoxy substitution on molecular structure, physicochemical and photovoltaic properties of 2D-conjugated polymers based on benzo [1, 2-b: 4, 5-b'] dithiophene and fluorinated benzothiadiazole. Chemical Physics Letters, 672, 63-69. 
Wu, C., Wu, Z., Wang, B., Li, X., Zhao, N., Hu, J., \& Wang, Q. (2017). Versatile donor$\pi$-acceptor-type aggregation-enhanced emission active fluorophores as both highly efficient nondoped emitter and excellent host. ACS Applied Materials \& Interfaces, 9(38), 32946-32956.

Yang, X., Duan, L., \& Ran, X. (2018). Photocatalytic degradation of organic dyes by a donor-acceptor type conjugated polymer: Poly (thiophene-1, 3, 4-oxadiazole) and its photocatalytic mechanism. Polymer International, 67(9), 1282-1290.

Yang, J., Dahlström, C., Edlund, H., Lindman, B., \& Norgren, M. (2019). pH-responsive cellulose-chitosan nanocomposite films with slow release of chitosan. Cellulose, 26(6), 3763-3776.

Yang, H., Liu, Y., Kong, L., Kang, L., \& Ran, F. (2019). Biopolymer-based carboxylated chitosan hydrogel film crosslinked by $\mathrm{HCl}$ as gel polymer electrolyte for all-solid-sate supercapacitors. Journal of Power Sources, 426, 47-54.

Yang, L., Zhao, B., Wu, H., Liu, J., Liu, H., Wang, J., ... Gao, C. (2019). High lying energy of charge-transfer states and small energetic offsets enabled by fluorinated quinoxaline-based alternating polymer and alkyl-thienyl side-chain modified non-fullerene acceptor. Organic Electronics, 66, 63-69.

Yoshioka, H., Izumi, C., Shida, M., Yamaguchi, K., \& Kobayashi, M. (2017). Repeatable adhesion by proton donor-acceptor interaction of polymer brushes. Polymer, 119, 167-175.
Yu, L., Liu, J., He, S., Huang, C., Gong, Z., Gan, L., ... Long, M. (2020). N-doped rGO/C@ Si composites using sustainable chitosan as the carbon source for lithium-ion batteries. Applied Surface Science, 501, Article 144136.

Zainudin, A. A., Fen, Y. W., Yusof, N. A., Al-Rekabi, S. H., Mahdi, M. A., \& Omar, N. A. S. (2018). Incorporation of surface plasmon resonance with novel valinomycin doped chitosan-graphene oxide thin film for sensing potassium ion. Spectrochimica Acta Part A: Molecular and Biomolecular Spectroscopy, 191, 111-115.

Zhang, L., Qin, M., Yu, Y., Zhang, M., Zhao, X., Qian, J., ... Wu, H. (2019). Preparation of ternary $\mathrm{Pt}-\mathrm{NiO}-\mathrm{ZnO}$ hybrids and investigation of its photocatalytic performance toward methyl orange. Journal of Materials Science Materials in Electronics, 30(5), 5158-5169.

Zhang, L., Zeng, Y., \& Cheng, Z. (2016). Removal of heavy metal ions using chitosan and modified chitosan: A review. Journal of Molecular Liquids, 214, 175-191.

Zhou, N., Dudnik, A. S., Li, T. I., Manley, E. F., Aldrich, T. J., Guo, P., \& Chang, R. P. (2016). All-polymer solar cell performance optimized via systematic molecular weight tuning of both donor and acceptor polymers. Journal of the American Chemical Society, 138(4), 1240-1251.

Zolfagharian, A., Kaynak, A., Khoo, S. Y., \& Kouzani, A. Z. (2018). Polyelectrolyte soft actuators: 3D printed chitosan and cast gelatin. 3D Printing and Additive Manufacturing, 5(2), 138-150. 